\title{
Impact of e-cigarettes on colonic mucosa and the role of recovery: involvement of oxidative and inflammatory pathway
}

\author{
Heba O. Mohammed ${ }^{1} \cdot$ Eman Ahmed Alaa El-Din ${ }^{2}$ (D) Azza I. Farag ${ }^{1}$ \\ Received: 24 March 2021 / Accepted: 18 July 2021 / Published online: 26 July 2021 \\ (C) The Author(s), under exclusive licence to Springer-Verlag GmbH Germany, part of Springer Nature 2021
}

\begin{abstract}
Electronic cigarettes (e-cigarettes) (EC) are often advertised as a safer alternative to conventional cigarettes. Its widespread use has led to increased interest in its adverse health effects, thanks to few restrictions and a lack of regulatory guidelines. The study aimed to evaluate the influence of exposure to e-cigarette aerosol inhalation in rat colon model and conduct a follow-up after cessation of exposure. The experiment included 30 male adult Albino rats. The animals were divided into three groups: group I (control), non-exposed animals; group II (exposed), was exposed to electronic cigarette liquid vapor for four consecutive weeks; and group III (recovery), was followed up for another 4 weeks after exposure to an e-cigarette as exposed group and for the same duration. In the exposed group, malondialdehyde (MDA) and total nitric oxide (NO) increased significantly in colonic tissue, while superoxide dismutase (SOD) decreased. On histological examination, colonic mucosa showed distortion and loss of its epithelial lining with heavy inflammatory cell infiltration. Also, there was a significant decrease in periodic acid-Schiff-positive goblet cells and area percent of proliferating cell nuclear antigen expression. Tumor necrosis factor-alpha (TNF $\alpha)$ expression significantly increased in colonic mucosa. After 4 weeks of EC cessation, the colonic mucosal histological structure showed recovery with downregulated TNF $\alpha$ immunoexpression and restored oxidant/antioxidant balance. In conclusion, the usage of electronic cigarettes resulted in marked pathological alterations in the colonic mucosa, which could be attributed to oxidative and inflammatory stresses. In contrast, the cessation of exposure led to recovery.
\end{abstract}

Keywords Electronic cigarettes $\cdot$ Nicotine $\cdot$ Gastrointestinal tract $\cdot \mathrm{TNF} \alpha \cdot$ Nitric oxide $\cdot$ PCNA

\section{Introduction}

Smoking is a worldwide public health problem; however, cessation could prevent it. But the powerful addictive nicotine properties represent an enormous problem, even for those with a strong desire to stop smoking. Various nicotine replacement

Responsible Editor: Mohamed M. Abdel-Daim

Eman Ahmed Alaa El-Din

Eman_alaa77@yahoo.com

Heba O. Mohammed

yassin_mekkawy@yahoo.com

Azza I. Farag

azza_ismael@hotmail.com

1 Department of Human Anatomy \& Embryology, Faculty of Medicine, Zagazig University, Zagazig, Egypt

2 Department of Forensic Medicine and Clinical Toxicology, Faculty of Medicine, Zagazig University, Zagazig 44519, Egypt strategies have been developed, including the e-cigarettes, which are considered a harm-reduction strategy. They may improve the general health of smokers and lead to smoking cessation (Rouabhia 2020).

E-cigarettes and vaping devices are terms used to express electronic nicotine delivery systems (ENDS). They have been present in the world market since 1970 and became widely popular in the USA, mainly among the youth (Etter and Bullen 2011). Different improvements have resulted in numerous generations of e-cigarette, with the latest called podbased e-cigarettes in the shape of a USB flash (the JUUL) (Hind III et al. 2018).

The marked increase in consumption of e-cigarettes is due to fruitful social media-based marketing and a widespread of tempting flavors, in addition to the concept that they are risk-free alternatives to combustible cigarettes. Recently, this notion of risk-free use has been challenged. Most e-liquids contain harmful chemicals like propylene glycol (PG), glycerol (Gly), flavorings, and impurities, all of which may have adverse health effects besides the 
highly addictive properties of nicotine. This emerging hazard has directed great attention to establish research and regulations for controlling the quality and composition of the used constituents in these nicotine devices (Alasmari et al. 2019; Gentzke et al. 2019; Parraga and Morissette 2020).

Different studies reported marked impairment of both respiratory bacterial and viral clearance after exposure to e-cigarette aerosols for 2 weeks, which increased the susceptibility to influenza and coronavirus infections. In addition, evidence of human respiratory and systemic inflammation has been distinguished in the plasma and bronchoalveolar lavage samples from e-cigarette users, with raised inflammatory biomarkers (Singh et al. 2019; Song et al. 2020).

Moreover, the relation between the use of e-cigarettes and their stimulatory effect on cancer progression or development has been proposed, in addition to their DNA devastating effect and damage to the repair pathways (Mravec et al. 2020). Crotty Alexander et al. (2020) confirmed that all chemical constituents of e-cigarette and vaping aerosols have the potential risk of inducing distinct health hazards throughout the body, either similar to or different from those caused by nicotine or traditional tobacco smoke.

Eliakim and Karmeli (2003) have provided further evidence for distinct and different effects of nicotine on small and large bowel. Nicotine at a dose protective to the colon could decrease IL-10 and increase IL- 6 production in the small bowel and had a biphasic outcome on IL-2. On the other hand, its only effect in the colon was the significant decrease of IL-2 levels in acute and chronic administration. Thus, nicotine administration decreased anti-inflammatory mediator (IL-10) levels in the small bowel and increased the proinflammatory mediator (IL-6), possibly contributing to mucosal damage in that region. There was no correlation between mucosal or blood levels of the cytokines examined. Other authors have found, in different settings, similar effects of smoking/ nicotine on the proinflammatory mediators IL-8, IL-1, and tumor necrosis factor in colonic mucosa (Madretsma et al. 1996; Sher et al. 1999).

The gastrointestinal tract is occupied by different microbiota that illustrates the regulation of several chronic diseases such as inflammatory bowel diseases (IBD), cardiovascular diseases, cancers, and rheumatoid arthritis. Ecigarettes significantly affect the oral microbiome; however, little is known about their significant impact on the gut microbiome and the gut barrier (Stewart et al. 2018; Pushalkar et al. 2020).

Therefore, this study was set out to assess the impact of ecigarette aerosol inhalation (nicotine-containing) on the colon and provide insights into its potential systemic health effects, and to detect how far these impacts can be improved after cessation of smoking.

\section{Material and methods}

\section{Chemical}

E-vapor was generated from an electronic cigarette refill bottle composed of a $2.5-\mathrm{mL}$ liquid tank in Pyrex glass and a rechargeable lithium battery (3.7 Volt EH IMR 18650; $2000 \mathrm{mAh}$ ), coupled with a dual coil atomizer (2Ohm stainless steel resistance). E-liquid was purchased from commercially available products in Egypt (Dollars Blends Comp). Every $1 \mathrm{ml}$ of liquid contains vegetable glycerin, propylene glycol (PG), natural flavorings, and nicotine $18 \mathrm{mg} / \mathrm{mL}$.

\section{Animals}

Thirty adult male Wistar Albino rats (outbred rats) were brought from the Animal House of Zagazig Faculty of Medicine, weighing approximately 180-200 g. Animals were kept in clean cages of plastic in a well-controlled temperature and humidity facility with a constant 12-h light/dark cycle. Food and tap water were accessible ad libitum during the study period. The experimental procedure was started after a week of acclimatization. This study was performed according to the guidelines of the Institutional Animal Care and Use Committee, Zagazig University (ZU-IACUC) and the guidelines contained in the guide for the care and use of laboratory animals, approval number (ZU-IACUC/3/F/12/2021).

\section{Experimental design}

After 7 days' adaptation, the rats were distributed randomly into three groups:

Group I (control): composed of ten non-exposed animals.

Group II (exposed group): ten animals were exposed using a whole-body mode. The inhalation chamber formed of a propylene box $(38 \times 26.5 \times 19 \mathrm{~cm})$, and its capacity was $19 \mathrm{~L}$. The pump (0.18 kW; 1.4/1.6 A; $230 \mathrm{~V} ; 50 / 60 \mathrm{~Hz})$ was connected to one side of that box, while aerosol of e-cigarette was pumped on the other side. That technique generates air flow to flow inside of the chamber. Animals ( 2 rats each time) were exposed to the consumption of $1 \mathrm{~mL} /$ day of e-liquid containing $18 \mathrm{mg} / \mathrm{mL}$ of nicotine. Each treatment cycle consisted of 17 -s puff ( $6 \mathrm{~s}$ on, $5 \mathrm{~s}$ off, $6 \mathrm{~s}$ on) followed by a 20 -min stop. The voltage of the e-cigarette was adjusted at 5.5 all over the whole experiment. By the end of each cycle, the rats were transferred to a clean chamber to begin the next one. Animals were exposed to $11 \mathrm{cycles} /$ day for five consecutive days/week for 4 weeks (Canistro et al. 2017).

Group III (recovery group): ten animals were kept in a clean chamber for another 4 weeks after being exposed to the e-cigarette as the exposed group and for the same duration (Chéruel et al. 2017). 
At the end of the experiment, the animals were injected intraperitoneally with thiopental $(50 \mathrm{mg} / \mathrm{kg})$ (Kanjana et al. 2013); their hearts were exposed and perfused by saline solution through the left ventricle till fluid came out from the right atrium, which after being opened, was blood-free. The colon specimens were dissected out after laparotomy and processed for histological study. We harvested two colonic samples from each animal: one was homogenized by immersion in ice-cold $50 \mathrm{mM}$ sodium phosphate buffer ( $\mathrm{pH} 7.4$ ) with $0.1 \mathrm{mM}$ ethylene diamine tetraacetic acid (EDTA), while the other specimen was fixed in $10 \%$ formol for the histopathological procedure.

\section{Lipid peroxidation estimation and oxidative enzyme assay}

The supernatant resulted from the homogenized colonic specimen was centrifuged at $1000 \mathrm{~g}$ for $20 \mathrm{~min}$ at $4 \mathrm{C}$ to be separated. The supernatant was analyzed for MDA, nitric oxide (NO), and superoxide dismutase (SOD):

- Lipid peroxidation was detected by measuring malondialdehyde (MDA) (Rayaman et al. 2015). It was measured colorimetrically by a commercially available kit (Biodiagnostic, Cairo, Egypt) according to Lapenna et al. (2001).

- $\quad$ Superoxide dismutase (SOD) and nitric oxide (NO) were measured by a commercially available kit (Biodiagnostic, Cairo, Egypt) according to Grace Nirmala and Narendhirakannan (2011) and Lundberg et al. (1997).

\section{Light microscopic examination:}

The fixed samples in $10 \%$ formol saline were processed, dehydrated, using ethanol and xylene, and then embedded in paraffin wax. Sections of 5- $\mu \mathrm{m}$ thickness were obtained and prepared from the colonic specimens for the following stains:

The colonic structure was observed using hematoxylineosin staining (H\&E) for detecting the structural integrity of the colon, and periodic acid-Schiff (PAS) staining was used to detect mucus-containing goblet cells (Ding et al. 2020). Hematoxylin $(\mathrm{H})$ \& eosin $(\mathrm{E})$ and periodic acid-Schiff (PAS) staining were performed according to the method of Bancroft and Gamble (2008).

- Immunohistochemical staining for:

\section{-Anti-proliferating cell nuclear antigen (PCNA)}

Immunohistochemical staining was processed using primary antiserum to PCNA (Clone PC 10, DAKO A/S Denmark). The primary antibody was diluted in Tris-buffered saline with a dilution of 1:50, as determined by the datasheet. The sections were incubated with the primary antibody overnight at $+4{ }^{\circ} \mathrm{C}$. Enough biotinylated secondary antibodies were applied to cover the specimen; then, the binding of the primary antibody was distinguished by using a commercial avidinbiotin-peroxidase detection system (DAKO, Carpenteria, USA). A mouse monoclonal antibody was applied in place of the primary antibody to act as a negative control. Small intestine sections were used as a positive control for (PCNA). The slides were stained with diaminobenzene and counterstained with hematoxylin; then, slides were dehydrated in $95 \%$ ethanol, cleared in xylene, and then coverslips were mounted using two drops of DPX mounting medium (Abdel-Dayem 2009).

-Tumor necrosis factor-alpha (TNF $\alpha)$

Immunostaining was done using TNF-alpha IHC Antibody (polyclonal, Abbiotec, San Diego, CA, USA) diluted at 1:80 in phosphate-buffered saline (PBS). The primary antibody was used in a dilution of 1:50 by adding phosphate-buffered saline. The specimen sections were incubated with the primary antibody overnight at $+4{ }^{\circ} \mathrm{C}$; then, secondary antibodies were applied to cover the specimen. Detection of binding the primary antibody was performed with a commercial avidinbiotin-peroxidase detection system (DAKO, Carpenteria, USA). Phosphate-buffered saline was utilized instead of primary antibody to act as a negative control. Sections of human mammary cancer were a positive control for $\mathrm{TNF} \alpha$. The slides were subjected to (DAB) and counterstained with hematoxylin (Kim et al. 2011).

\section{Morphometric analysis}

- The morphometric study was performed using the image analyzer (the Image J software plugin) in the Anatomy and Embryology Department, Faculty of Medicine, Zagazig University, Egypt. Random microscopic areas were under 400 high power fields. A mean of 15 readings was assessed from 5 serial sections from each animal within each group as follow:

- PAS stained sections were analyzed morphometrically to count the number of goblet cells in each field manually.

- Sections of each group stained with PCNA and TNF $\alpha$ were subjected for estimation of the area percent of positively immune reaction that was done after image splitting. Images were split into RGB stacks; then, the red stack was accustomed to a threshold to highlight it with a binary mask.

\section{Statistical analysis}

Statistical analysis was carried out using Graph Pad Prism 5 "Graph Pad Software, San Diego, USA" and was performed by two studied groups, using analysis of variance test 
followed by Student-Newman-Keuls post hoc test with the value of $p<0.05$ considered statistically significant. The obtained data were stated as mean values and SE (standard error).

\section{Results}

\section{Assay of enzyme activity}

There was a significant increase in MDA and total NO in group II (exposed) compared to the other two groups. On the contrary, their levels decreased in the recovery group (III) but still significantly more than Group I (control). There was a significant decrease in the SOD level in the group exposed to e-cigarette compared to the other two groups. The SOD level increased in the recovery group but still significantly less than in the control group (Table 1).

\section{Histological results}

\section{$H \& E$}

Histological examination of colonic specimen sections from Group I (control animals) showed the normal architecture of the colon. They revealed folded mucosa with intact and continuous simple columnar epithelial lining, submucosa, and musculosa with multiple goblet cells within the lining of regularly organized tubular crypts (Fig. 1). On exposure to an aerosol of e-cigarette group II (exposed), the colonic specimen showed distorted mucosa with loss of continuity in its epithelial lining and heavy inflammatory cell infiltration. There were few goblet cells within the lining of crypts (Fig. 2). Group III (recovery) revealed marked improvement in the histological structure of colonic specimens, as restoring of their mucosal lining with few inflammatory infiltrations and an apparent increase of goblet cells (Fig. 3).

\section{PAS staining}

Group I (control animals) revealed abundant goblet PASpositive cells in the crypts of colonic mucosa (Fig. 4a), while group II (exposed) exhibited very scarce PAS-positive goblet cells (Fig. 4b). Group III (recovery) showed many PASpositive goblet cells (Fig. 4c).

\section{Anti-PCNA}

Group I (control animals) showed multiple PCNA-positive cells within the mucosal cells (Fig. 5a), while group II (exposed) revealed a marked decrease of PCNA-positive cells (Fig. 5b). Group III (recovery) showed restoration of positive cells in colonic mucosa (Fig. 5c).

\section{TNFa immunohistochemical staining}

Group I (control animals): the section revealed scanty TNF $\alpha$ positive expression (Fig. 6a), while Group II (exposed) showed marked expression of TNF $\alpha$ (Fig. 6b). Positive immunoexpression of TNF $\alpha$ was markedly less in Group III (recovery) (Fig. 6c).

\section{Morphometric results}

There was a significant decrease in PAS-positive goblet cells and area percent of PCNA expression in group II (exposed) compared to the other two groups. Conversely, their levels elevated in group III (recovery) but still significantly less than group I (control). There was a significant increase in the area percent of TNF $\alpha$ expression in group II (exposed) compared to the other two groups. On the other hand, TNF $\alpha$ expression decreased in percent in group III (recovery) but still significantly higher than group I (control) (Table 2).

\section{Discussion}

Electronic cigarettes (e-cigarettes) are widely used all over the world. They are thought to be a safer substitute for combustible cigarette smoking and an effective smoking cessation aid. They are designed to provide the desired nicotine dose without burning tobacco; hence, they have reduced adverse general and oral health effects compared to combustible cigarettes. However, the differential effects of e-cigarettes and combustible cigarettes have been based on self-reported perceptions. Also, young people who are smoking e-cigarettes

Table 1 Comparison among different studied groups regarding mean values of MDA, SOD, and NO

\begin{tabular}{llll}
\hline Parameter Mean \pm SE & Group I & Group II & Group III \\
\hline MDA (nmol/mg) & $\mathbf{5 . 4 9 8} \pm 0.1819$ & $12.02 \pm 0.3343 P<0.05^{\mathrm{a}}$ & $\mathbf{8 . 3 3 0} \pm 0.2392 P<0.05^{\mathrm{a} \& \mathrm{~b}}$ \\
SOD (U/mg) & $\mathbf{6 1 . 2 0} \pm \mathbf{2 . 2 6 0}$ & $\mathbf{2 1 . 3 1} \pm 1.133 P<0.05^{\mathrm{a} \& \mathrm{~b}}$ & $\mathbf{2 9 . 4 9} \pm 0.3054 P<0.05^{\mathrm{a} \& \mathrm{~b}}$ \\
NO (nmol/g tissue) & $257.2 \pm 9.401$ & $\mathbf{6 0 8 . 2} \pm 7.086 P<0.05^{\mathrm{a}}$ & $402.6 \pm 7.062 P<0.05^{\mathrm{a} \& b}$ \\
\hline
\end{tabular}

$N S$ non-significant $(P>0.05)$

$P<0.05=$ statistically significant, $\mathrm{a}=$ versus group $\mathrm{I}, \mathrm{b}=$ versus group II 
Fig. 1 Photomicrographs of a colonic section from group I (control group). (a) shows normal mucosa (M), submucosa (SB), and musculosa (Ms) (H\&E, $\times 100$ ). (b) shows folded mucosa with intact and continuous simple columnar epithelial lining (arrow), multiple goblet cells (zigzag green arrow), and regularly organized tubular crypts (Cry) (H\&E, $\times 400$ )

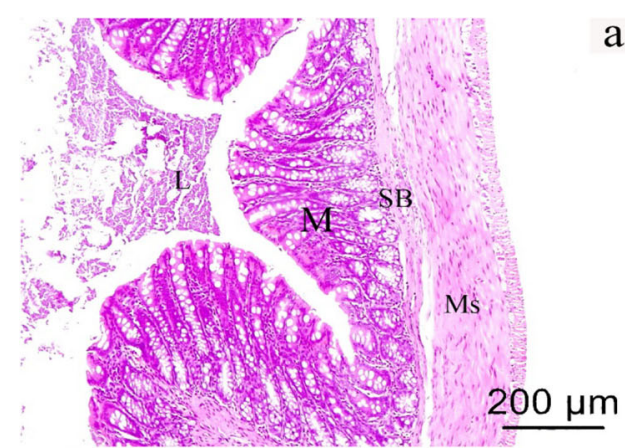

and have never engaged in combustible cigarette smoking are increasing. This necessitated more detailed research on the health effects of e-cigarettes (Rouabhia 2020). Therefore, the present study evaluated the impact of the exposure to ecigarette vapor (with nicotine) on colonic mucosa and conducted a follow-up after smoking cessation.

The biochemical results of our study illustrated an imbalance between the oxidants and antioxidants, where there was a significant decrease in SOD and an increase in MDA and NO levels in the exposed group (II) compared to the other groups. This agreed with the results of previous studies (Verschuere et al. 2012; Bhattacharyya et al. 2014).

These biochemical results may explain the induced gastrointestinal pathology, in the form of discontinuation of the GI tract barrier, thereby increasing intestinal permeability and contributing to the inflammation, as reported by different authors, declaring that reduced SOD activity in the gut caused gastric ulcer (Kwiecien et al. 2014; Vona et al. 2021).

Moreover, our results were congruent with Marczylo (2020), who reported that systemic effects of e-cigarettes were identified using oxidative stress and inflammation biomarkers, in addition to the significant increase in lipid peroxidation. They added that the greater exposure to free radicals is directly related to nicotine exposure from e-cigarettes with nicotine.

The dysregulation of nitric oxide $(\mathrm{NO})$ production detected in our study goes in hand with the results of Achitei et al. (2013), Li et al. (2015), Yang et al. (2015), Berkowitz et al. (2018), and Ismail and Aboulkhair (2018). They reported that smokers and animals exposed to cigarette smoke have significantly high levels of systemic oxidative stress biomarkers, which can negatively affect the susceptible tissues, like the gastrointestinal tract.

In addition, near our results, Kuntic et al. (2020) detected disturbed NO signaling in the endothelium of mice exposed to e-cigarettes and severe oxidative stress in the aorta, lung, and brain of animals after e-cigarette vapor exposure. Moreover, Papoutsopoulou et al. (2020) mentioned that the decreased nitric oxide levels could prevent intestinal mucosal injury, helping to restore epithelial continuity, while its high production resulted in deleterious effects via enhancing the adverse effects of other reactive oxygen species (ROS).
Fig. 2 Photomicrographs of a colonic section from group II (exposed group). (a) shows mucosa (M), submucosa (SB) with blood vessel (Bv), and musculosa (Ms) and serosa (S) (H\&E, $\times 100)$. (b) shows distorted mucosa with loss of continuity in its epithelial lining (arrow) with heavy inflammatory cell infiltration (red asterisk). Note, few goblet cells (zigzag green arrow) within lining of crypts (Cry). (c) shows heavy infiltration of inflammatory cells (red asterisk) with disturbed crypts (arrow) and scares goblet cells $(H \& E, \times 400)$

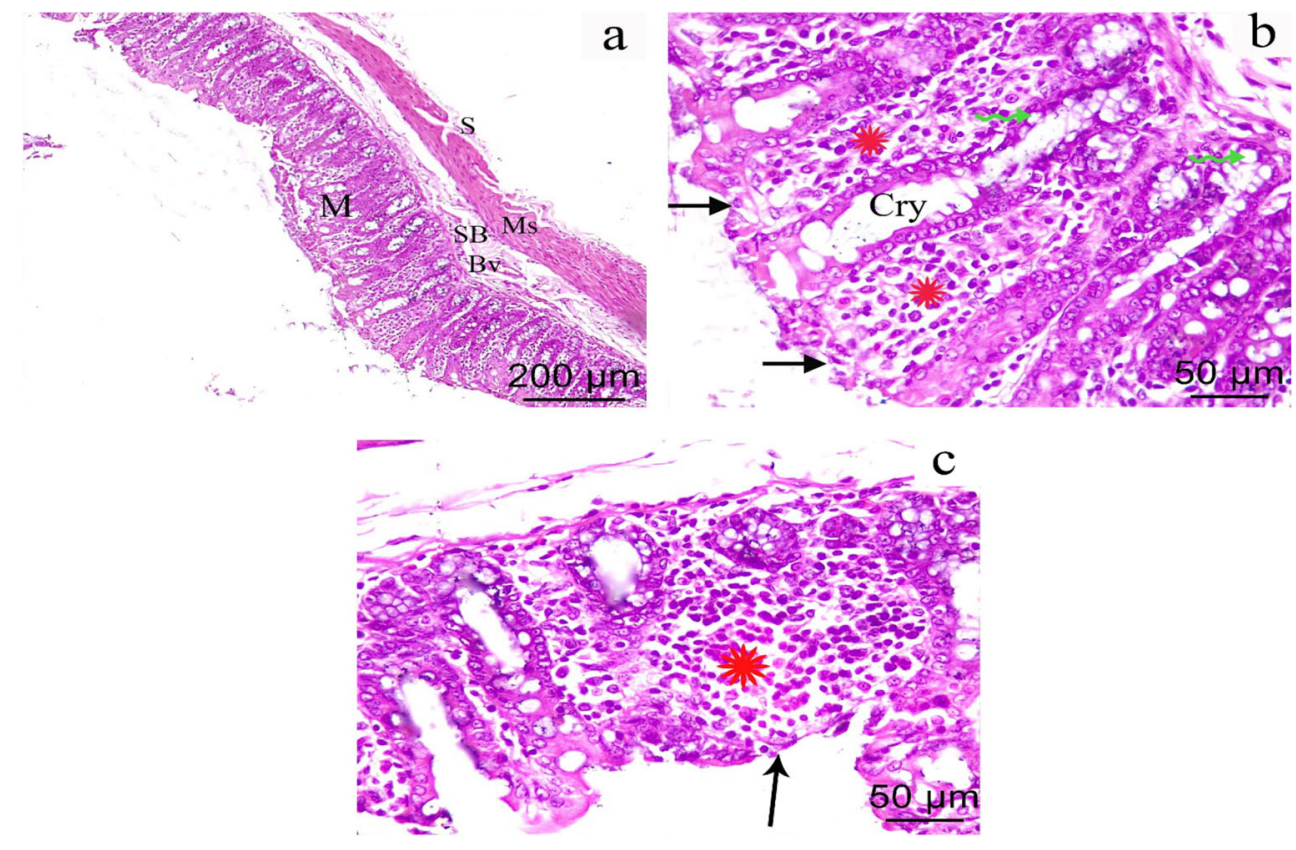




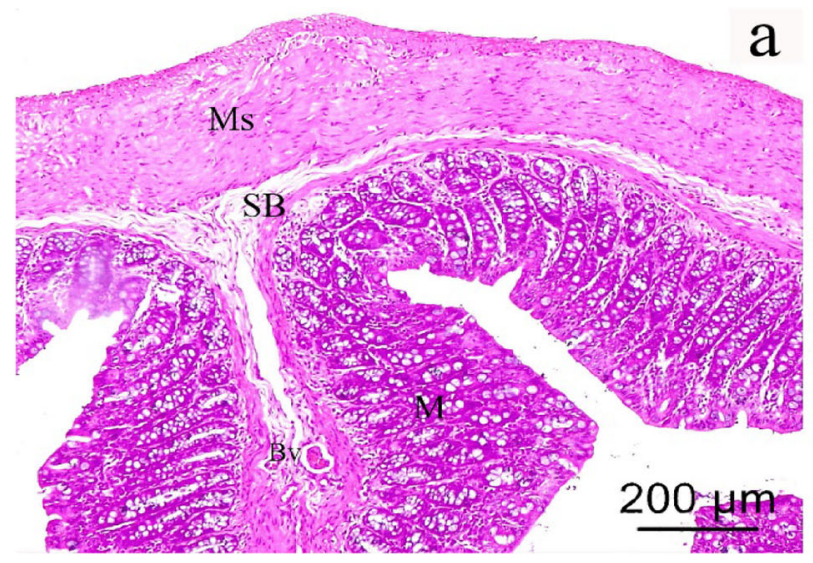

Fig. 3 Photomicrographs of a colonic section from group III (recovery group). (a) shows nearly normal mucosa (M), submucosa (SB) with congested blood vessel $(\mathrm{Bv})$, and musculosa $(\mathrm{Ms})(\mathrm{H} \& \mathrm{E}, \times 100)$. (b) shows folded mucosa with intact and continuous simple columnar

Moreover, Abdel Mohsen and Ahmed (2019) declared that iNOS is involved in colitis pathogenesis. iNOS could produce high NO levels that interact with free radicals creating more toxic compounds, which trigger tissue damage by modifying the structure and function of DNA, proteins, and lipids.

In the present study, colonic specimens from the exposed group (II) showed distorted mucosa with loss of folding and the continuity of its epithelial lining, heavy inflammatory cell infiltration, and few goblet cells within the lining of crypts. They were lost or distorted in most areas. Similar findings were recorded in acetic acid-induced colitis of previous studies (Sen et al. 2017; De Santana Souza et al. 2017; Abdel Mohsen and Ahmed 2019; Malago and Sangu 2015). Also, Sharma et al. (2021) reported the presence of intermittent areas of epithelial losses after acute exposure of mice (1 week)

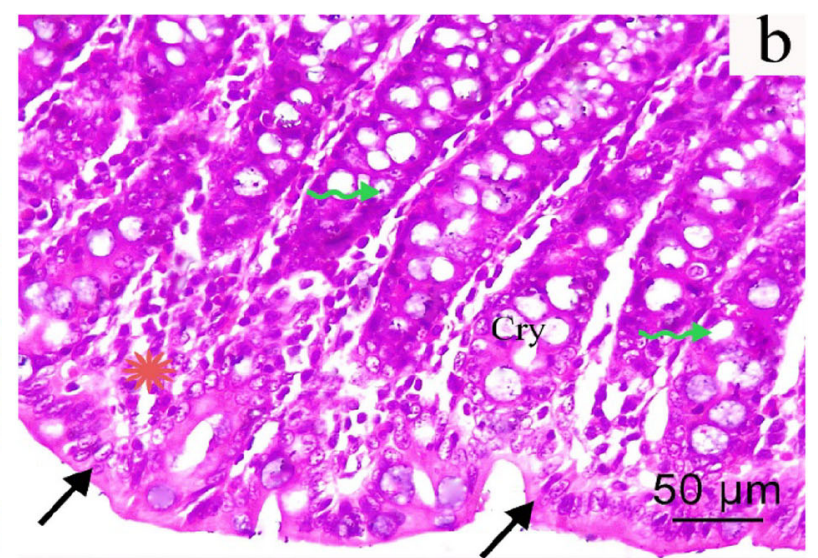

epithelial lining (arrow) and few inflammatory cell infiltration (red asterisk); multiple goblet cells (zigzag green arrow) are seen within the lining of crypts (Cry) (H\&E, $\times 400)$

to nicotine-containing e-cig aerosols, while the inflammatory infiltrates within the colonic submucosa were enormous in chronic exposure (3 months).

Near our results, Ismail and Aboulkhair (2018) observed congeneric histopathological changes in acetic acid-induced colitis. This colitis is extremely similar to human ulcerative colitis regarding microscopic features, pathogenesis, and inflammatory mediators.

The colonic pathology observed in our study can be traced back to the effect of cigarette smoke that contains high concentrations of reactive oxygen metabolites (ROMs), as nitric oxide and superoxide in the gas phase, and semiquinoneradicals and metal ions in the tar phase. These ROMs allow the change of hydrogen peroxide to the highly reactive hydroxyl radical and peroxides, which in turn may lead to
Fig. 4 Photomicrographs of sections in distal colon of a rat from each experimental group. (a) Group I (control group) shows multiple PAS-positive goblet cells within the crypts ( arrows). (b) Group II shows few PASpositive goblet cells (arrow). (c) Group III shows apparent increase in PAS-positive cells (arrow) (PAS $\times 400)$
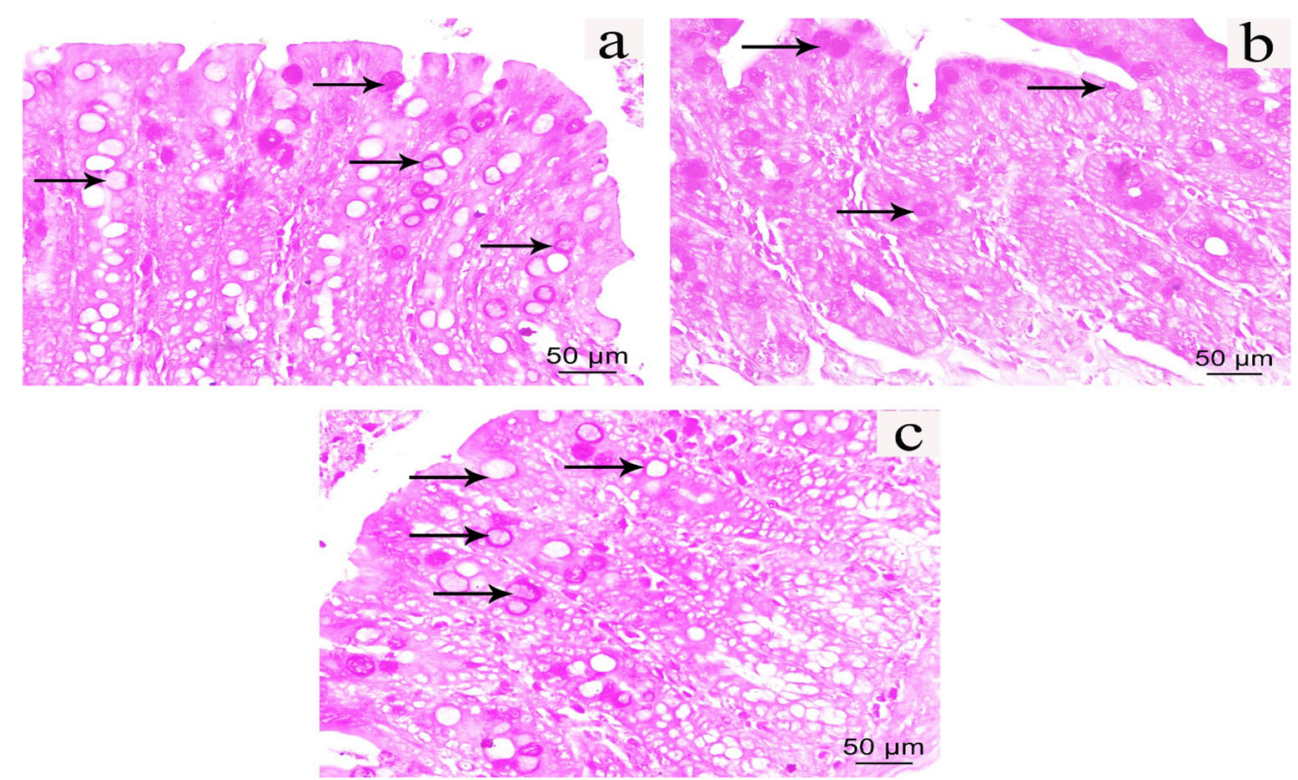
Fig. 5 Photomicrographs of sections in distal colon of a rat from each experimental group. (a) Group I (control group) shows multiple PCNA-positive cells within the mucosal cells (tailed arrows). (b) Group II shows few PCNA-positive cells mainly in submucosa (tailed arrow). (c) Group III shows apparent increase in PCNA-positive cells (tailed arrow).

(Immunohistochemistry stain for PCNA $\times 400$ )

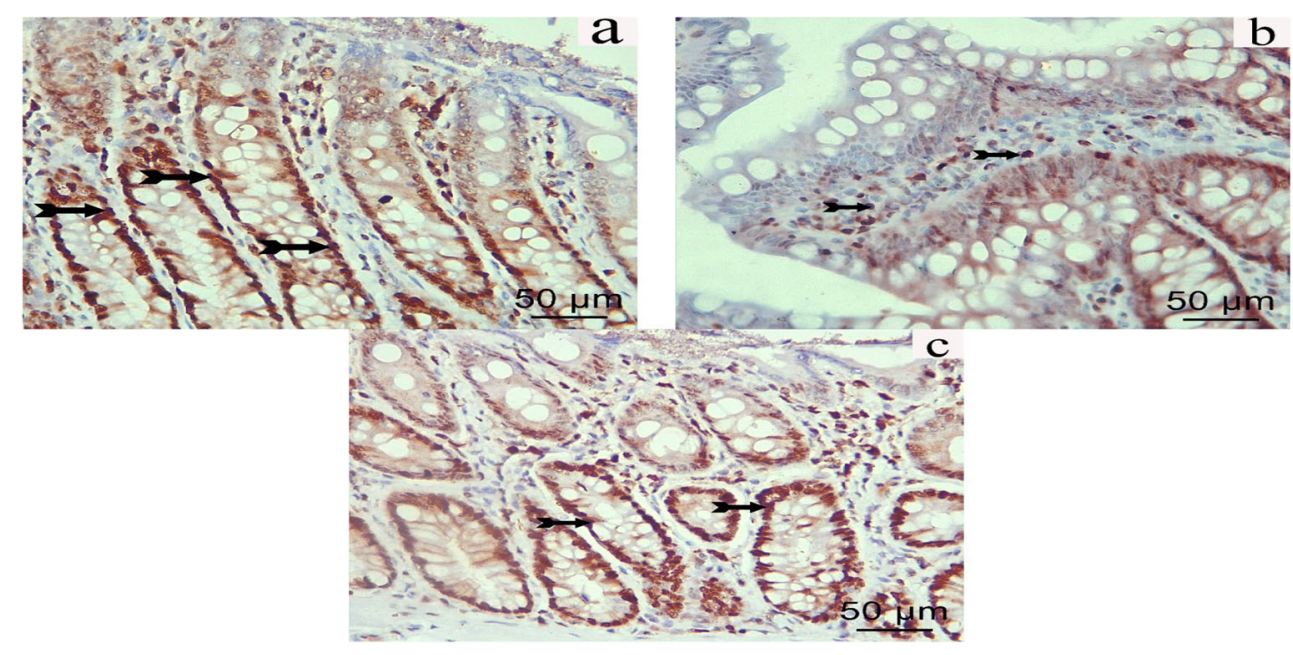

significant tissue necrosis and mucosal dysfunction (Verschuere et al. 2012). Kwiecien et al. (2014) referred the intestinal injury as the effect of the inflammatory cells that release proteases and lipid mediators.

Another explanation was declared by Ghosh et al. (2020) and Wang et al. (2016), who reported that exposure to nicotine-free e-cigarettes causes loss of epithelial barrier integrity and increased susceptibility to inflammation due to a marked decrease in tight junction markers (TJ): occludin and zonula occludens (ZO1). They added that, in chronic repetitive exposure to e-cigarettes, multiple pro-inflammatory cytokines were either elevated significantly (IL-8, TNF $\alpha$ ) or displayed an increasing trend but did not show significance (Cxcl2).

Our results suggested that e-cigarette could precipitate ulcerative colitis owing to the observed heavy colonic infiltration with inflammatory cells in exposed rats (group II). This finding was confirmed morphometrically by the significant increase in the percent of tumor necrosis factor-alpha $(\mathrm{TNF} \alpha)$. In the same context, previous researches have marked ulcerative colitis with granulocytes and other leucocyte infiltrations into the site of mucosal inflammation and ulcers, which resulted in increased pro-inflammatory cytokines (TNF $\alpha$ and interleukin-6). These cytokines play a vital role in modulating the intestinal immune system, as macrophages and neutrophils are responsible for epithelial disruption and colonic injury (Karaca et al. 2010; Al-Rejaie et al. 2013). Also, Zucker et al. (2015) supported our results and detected eosinophilic infiltrations in ulcerative colitis.

The intestinal goblet cells are present throughout the intestinal tract, especially in the distal colon and rectum. They are highly polarized secretory cells involved in intestinal protection by producing several mediators, including the mucin and trefoil factor-3, which augments the mucus protective barrier
Fig. 6 Photomicrographs of sections in distal colon of a rat from each experimental group. (a) Group I (control group) shows scanty $\mathrm{TNF} \alpha$-positive cells (red arrow). (b) Group II shows marked expression of TNF $\alpha$ (red arrow). (c) Group III shows apparent few cells with positive $\mathrm{TNF} \alpha$ expression (red arrow). (Immunohistochemistry stain for $\mathrm{TNF} \alpha \times 400)$
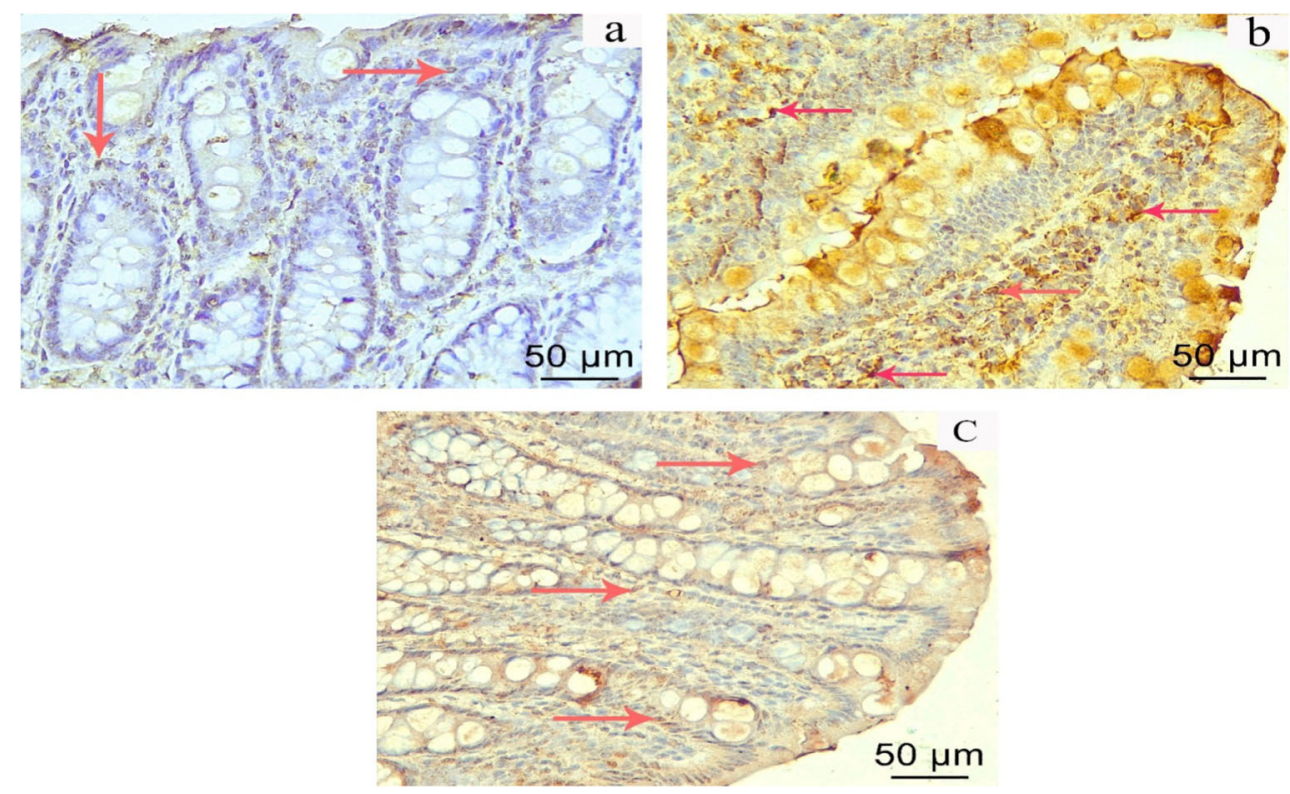
Table 2 Comparison among different studied groups regarding different morphometric parameters

\begin{tabular}{|c|c|c|c|}
\hline Parameter Mean $\pm \mathrm{SE}$ & Group I & Group II & Group III \\
\hline Number of PAS+ve goblet cells & $39.20 \pm 1.769$ & $14.90 \pm 0.8750 P<0.05^{\mathrm{a}}$ & $26.20 \pm 1.083 P<0.05^{\mathrm{a} \& \mathrm{~b}}$ \\
\hline Area percent of PCNA expression \% & $20.23 \pm 0.3391$ & $10.74 \pm 0.2168 P<0.05^{\mathrm{a}}$ & $18.33 \pm 0.2783 P<0.05^{\mathrm{a} \& \mathrm{~b}}$ \\
\hline Area percent of TNF $\alpha$ expression $\%$ & $5.349 \pm 0.3504$ & $22.44 \pm 0.7888 P<0.05^{\mathrm{a}}$ & $9.110 \pm 0.4971 P<0.05^{\mathrm{a} \& \mathrm{~b}}$ \\
\hline
\end{tabular}

NS non-significant $(P>0.05)$

$P<0.05=$ statistically significant, $\mathrm{a}=$ versus group $\mathrm{I}, \mathrm{b}=$ versus group II

properties against chemically induced ulceration, and promotes epithelial restoration after mucosal injury. This released mucus gel layer acts as an intestinal lubricant, a niche for colonization of commensal-flora to get their nutrients, and restricts the passage of molecules into the mucosa (Bergstrom et al. 2008; Al-Rejaie et al. 2013).

In the current work, morphometric results revealed a significant decrease of PAS+goblet cells number in the mucosa of group II (exposed) animals compared to other groups. These results agreed with Nowarski et al. (2015) and Ismail and Aboulkhair (2018). Kasinathan et al. (2018) explained this decreased number of goblet cells by being a part of tissue destruction that occurred through the inflammatory process. This marked reduction of mucin-producing-goblet cells and the mucus layer explains the increased inflammation in the exposed group in our study. These results were similar to previous studies, which reported that ulcerative colitis was manifested by mucosal barrier dysfunction, particularly in epithelial goblet cells and their mucus production (Nowarski et al. 2015).

Moreover, our results revealed a significant decrease in PCNA immune expression in the exposed group compared to other groups. These findings coincided with Helal et al. (2020), who detected decreased PCNA expression in rats with ulcerative colitis. Additionally, Glover et al. (2017) observed a low proliferation rate under the impact of low-grade continuous inflammation. Also, our findings were supported by Sharma et al. (2021), who stated that e-cigarettes induce gut inflammation.

Many studies tested chemicals found in most basic ecigarette aerosols (>99\%) (propylene glycol and glycerol) and proved that chronic and repetitive exposure to aerosols of electronic-cigarette induces harmful effects on the oral mucosa and respiratory system (Pushalkar et al. 2020; Madison et al. 2020; Crotty Alexander et al. 2018).

However, the findings of some other studies were against our results, as they reported that nicotine performs a direct anti-inflammatory impact on monocytes and $\mathrm{T}$ cells through the direct motivation of the cholinergic anti-inflammatory pathway (inhibition of NFkB signaling). They added that it has a protective role against the advance and progression of ulcerative colitis. These results may be due to short-term exposure to nicotine (Suenaert et al. 2003), different regional effects of nicotine on the small bowel and colonic cytokine mucosal levels (Eliakim and Karmeli 2003), or the use of sidestream smoking (Wang et al. 2012).

Also, Sharma et al. (2021) found no significant alteration in colonic gene expression in acute exposure to nicotine-free ecigarettes while recorded marked changes in gene expression in chronic exposure. They added that exposure to nicotinecontaining e-cigarettes reversed these differences. This is congruent with nicotine anti-inflammatory and barrier-tightening effects, which were also proved in humans upon chronic, not acute exposures. They finally concluded that repeated exposure to e-cigarettes over months altered transcriptional programs of three main inter-related genes concerned with cellular response to stress and stimuli, mucosal response to infection and inflammation, and anti-oncogenic pathways.

Although prior research has studied adverse effects of intraperitoneal injection of nicotine or e-liquid on rat health (Valença et al. 2004; Golli et al. 2016), the exposure in our study was designed to model firsthand e-cigarette vapor exposure, with rats exposed to EV generated from the devices used by actual e-cigarette users. Rats may have tinny ecigarette aerosol deposited on their fur that they might reingest when preening leading to far greater exposure to the gastrointestinal tract than e-cigarette users; however, the reason for using this model of exposure is that heating and vaporization of e-liquid alter the chemical composition and can create toxins such as formaldehyde and acrolein. These toxins may cause adverse effects directly on the airway and endothelial cells much more than other components of EV do (Jensen et al. 2015).

In our research, the recovery group revealed marked improvement in the histological structure of their colonic specimens, as restored mucosal lining with few inflammatory infiltrations and increased goblet cells. These findings may be due to the restoration of oxidant/antioxidant balance where MDA and total NO significantly decreased in levels, but SOD decreased. Our results matched with recent studies of Afzal et al. (2021) and Vona et al. (2021). They mentioned that the gastrointestinal mucosal injury could be prevented by the presence of adequate levels of SOD antioxidant enzymes, as they have both primary and secondary defense functions against both endogenous and exogenous toxins to counterbalance the free radical damaging effects of e-cigarettes. 
Therefore, increased SOD activity has been associated with ulcer healing in patients, indicating the importance of its antioxidant activity in promoting health (Bhattacharyya et al. 2014)

In addition, our findings agreed with the previous studies, which proved that royal jelly (RJ) protected against acetic acid-induced colitis, as it returned the balance between the oxidative enzymes to be similar to the control group. This, in turn, protects against colonic injury, thus approving its potent antioxidant and anti-inflammatory properties (Ismail and Aboulkhair 2018).

\section{Conclusion}

In conclusion, exposure to the vapor from nicotine-containing e-cigarettes can induce colonic mucosal toxicity and damage in adult male Albino rats. Such unpredicted adverse effects may involve inflammation and/or oxidative stress. However, cessation of exposure to e-cigarettes leads to improvement and partial restoration of colonic mucosal integrity. With the continuous rise in e-cigarettes use, further studies are mandatory to understand the direct short and long-term effects of exposure to vapor on several different target sites and toxicological pathways and to identify the active components in e-vapor.

Author contribution HOM, EAAE, and AIF contributed to the study conception, design, material preparation, investigations, data collection, and analysis. The first draft of the manuscript was written by HOM and AIF. All authors read, and approved the final manuscript.

Data availability The datasets used and/or analyzed during the current study are available from the corresponding author on reasonable request.

\section{Declarations}

Ethics approval The experimental protocol was approved by the Institutional Animal Care and Use Committee (ZU-IACUC), Faculty of Medicine, Zagazig University, Egypt, approval number (ZU-IACUC/3/F/ 12/2021).

Consent to participate Not applicable.

Consent for publication Not applicable.

Conflict of interest The authors declare no competing interests.

\section{References}

Abdel Mohsen M, Ahmed M (2019) Histological study on the effect of adipose mesenchymal stem cells derived microvesicles and the role of its RNA content on experimentally-induced ulcerative colitis in albino rats. Egyptian Journal of Histology 0:0-0
Abdel-Dayem M (2009) Histological and immunohistochemical changes in the adult rat testes after left experimental varicocele and possible protective effects of resveratrol. Egypt J Histol 32:81-90

Achitei D, Ciobica A, Balan G, Gologan E, Stanciu C, Stefanescu G (2013) Different profile of peripheral antioxidant enzymes and lipid peroxidation in active and non-active inflammatory bowel disease patients. Dig Dis Sci 58:1244-1249

Afzal SM, Vafa A, Rashid S, Barnwal P, Shahid A, Shree A, Islam J, Ali N, Sultana S (2021) Protective effect of hesperidin against N,N'dimethylhydrazine induced oxidative stress, inflammation, and apoptotic response in the colon of Wistar rats. Environ Toxicol 36: 642-653

Alasmari F, Crotty Alexander LE, Hammad AM, Bojanowski CM, Moshensky A, Sari Y (2019) Effects of chronic inhalation of electronic cigarette vapor containing nicotine on neurotransmitters in the frontal cortex and striatum of C57BL/6 mice. Front Pharmacol 10

Al-Rejaie SS, Abuohashish HM, Al-Enazi MM, Al-Assaf AH, Parmar MY, Ahmed MM (2013) Protective effect of naringenin on acetic acid-induced ulcerative colitis in rats. World J Gastroenterol 19: $5633-5644$

Bancroft, J. D. \& Gamble, M. 2008. Theory and practice of histological techniques, Elsevier health sciences.

Bergstrom KS, Guttman JA, Rumi M, Ma C, Bouzari S, Khan MA, Gibson DL, Vogl AW, Vallance BA (2008) Modulation of intestinal goblet cell function during infection by an attaching and effacing bacterial pathogen. Infect Immun 76:796-811

Berkowitz L, Schultz BM, Salazar GA, Pardo-Roa C, Sebastian VP, Alvarez-Lobos MM, Bueno SM (2018) Impact of cigarette smoking on the gastrointestinal tract inflammation: opposing effects in Crohn's disease and ulcerative colitis. Front Immunol 9:74

Bhattacharyya A, Chattopadhyay R, Mitra S, Crowe SE (2014) Oxidative stress: an essential factor in the pathogenesis of gastrointestinal mucosal diseases. Physiol Rev 94:329-354

Canistro D, Vivarelli F, Cirillo S, Babot Marquillas C, Buschini A, Lazzaretti M, Marchi L, Cardenia V, Rodriguez-Estrada MT, Lodovici M, Cipriani C, Lorenzini A, Croco E, Marchionni S, Franchi P, Lucarini M, Longo V, Della Croce CM, Vornoli A, Colacci A, Vaccari M, Sapone A, Paolini M (2017) E-cigarettes induce toxicological effects that can raise the cancer risk. Sci Rep $7: 2028$

Chéruel F, Jarlier M, Sancho-Garnier H (2017) Effect of cigarette smoke on gustatory sensitivity, evaluation of the deficit and of the recovery time-course after smoking cessation. Tob Induc Dis 15:15-15

Crotty Alexander LE, Drummond CA, Hepokoski M, Mathew D, Moshensky A, Willeford A, Das S, Singh P, Yong Z, Lee JH, Vega K, Du A, Shin J, Javier C, Tian J, Brown JH, Breen EC (2018) Chronic inhalation of e-cigarette vapor containing nicotine disrupts airway barrier function and induces systemic inflammation and multiorgan fibrosis in mice. Am J Phys Regul Integr Comp Phys 314:R834-r847

Crotty Alexander LE, Ware LB, Calfee CS, Callahan SJ, Eissenberg T, Farver C, Goniewicz ML, Jaspers I, Kheradmand F, King TEJR, Meyer NJ, Mikheev VB, Shields PG, Shihadeh A, Strongin R, Tarran R (2020) E-cigarette or vaping product use-associated lung injury: developing a research agenda. An NIH Workshop Report. Am J Respir Crit Care Med 202:795-802

De Santana Souza MT, Teixeira DF, De Oliveira JP, Oliveira AS, Quintans-Júnior LJ, Correa CB, Camargo EA (2017) Protective effect of carvacrol on acetic acid-induced colitis. Biomed Pharmacother 96:313-319

Ding F, Wu J, Liu C, Bian Q, Qiu W, Ma Q, Li X, Long M, Zou X, Chen $J$ (2020) Effect of xiaoyaosan on colon morphology and intestinal permeability in rats with chronic unpredictable mild stress. Front Pharmacol 11:1069 
Eliakim R, Karmeli F (2003) Divergent effects of nicotine administration on cytokine levels in rat small bowel mucosa, colonic mucosa, and blood. Isr Med Assoc J 5:178-180

Etter JF, Bullen C (2011) Electronic cigarette: users profile, utilization, satisfaction and perceived efficacy. Addiction 106:2017-2028

Gentzke AS, Creamer M, Cullen KA, Ambrose BK, Willis G, Jamal A, King BA (2019) Vital signs: tobacco product use among middle and high school students-United States, 2011-2018. Morb Mortal Wkly Rep 68:157-164

Ghosh P, Swanson L, Sayed IM, Mittal Y, Lim BB, Ibeawuchi S-R, Foretz M, Viollet B, Sahoo D, Das S (2020) The stress polarity signaling (SPS) pathway serves as a marker and a target in the leaky gut barrier: implications in aging and cancer. Life science alliance 3: e201900481

Glover M, Soni S, Ren Q, Maclennan GT, Fu, P. \& Gupta, S. (2017) Influence of chronic inflammation on Bcl-2 and PCNA expression in prostate needle biopsy specimens. Oncol Lett 14:3927-3934

Golli NE, Jrad-Lamine A, Neffati H, Dkhili H, Rahali D, Dallagi Y, EL Fazaa S (2016) Impact of e-cigarette refill liquid exposure on rat kidney. Regul Toxicol Pharmacol 77:109-116

Grace Nirmala J, Narendhirakannan RT (2011) Detection and genotyping of high-risk HPV and evaluation of anti-oxidant status in cervical carcinoma patients in Tamil Nadu State, India - a case control study. Asian Pac J Cancer Prev 12:2689-2695

Helal OK, Mansy A, Mohamed OM, Radwan HE (2020) The possible therapeutic effect of rebamipide and stem cell derivative microvesicles on experimentally provoked colitis in rats: histological and immuno histochemical study. Egyptian Journal of Histology 43:340-352

Hinds JT 3rd, Li X, Loukas A, Pasch KE, Perry CL (2018) Flavored cigars appeal to younger, female, and racial/ethnic minority college students. Nicotine Tob Res 20:347-354

Ismail D, Aboulkhair A (2018) Royal jelly protects against experimentally-induced ulcerative colitis in adult male albino rats: a histological study. Egyptian Journal of Histology 41:192-203

Jensen RP, Luo W, Pankow JF, Strongin RM, Peyton DH (2015) Hidden formaldehyde in e-cigarette aerosols. N Engl J Med 372:392-394

Kanjana K, Haygarth KS, Wu W, Bartels DM (2013) Laboratory studies in search of the critical hydrogen concentration. Radiat Phys Chem $82: 25-34$

Karaca T, Bayiroglu F, Yoruk M, Kaya MS, Uslu S, Comba B, Mis L (2010) Effect of royal jelly on experimental colitis induced by acetic acid and alteration of mast cell distribution in the colon of rats. Eur J Histochem 54:e35

Kasinathan NK, Subramaniya B, Sivasithamparam ND (2018) NF-kB/ twist mediated regulation of colonic inflammation by lupeol in abating dextran sodium sulfate induced colitis in mice. J Funct Foods 41: 240-249

Kim SH, Kim K, Ahn JH, Chang HK (2011) Increased expression of tumor necrosis factor-alpha in the rat hippocampus after acute homocysteine administration. Journal of epilepsy research 1:6-12

Kuntic M, Oelze M, Steven S, Kröller-Schön S, Stamm P, Kalinovic S, Frenis K, Vujacic-Mirski K, Bayo Jimenez MT, Kvandova M, Filippou K, Al Zuabi A, Brückl V, Hahad O, Daub S, Varveri F, Gori T, Huesmann R, Hoffmann T, Schmidt FP, Keaney JF, Daiber A, Münzel T (2020) Short-term e-cigarette vapour exposure causes vascular oxidative stress and dysfunction: evidence for a close connection to brain damage and a key role of the phagocytic NADPH oxidase (NOX-2). Eur Heart J 41:2472-2483

Kwiecien S, Jasnos K, Magierowski M, Sliwowski Z, Pajdo R, Brzozowski B, Mach T, Wojcik D, Brzozowski T (2014) Lipid peroxidation, reactive oxygen species and antioxidative factors in the pathogenesis of gastric mucosal lesions and mechanism of protection against oxidative stress - induced gastric injury. J Physiol Pharmacol 65:613-622
Lapenna D, Ciofani G, Pierdomenico SD, Giamberardino MA, Cuccurullo F (2001) Reaction conditions affecting the relationship between thiobarbituric acid reactivity and lipid peroxidesin human plasma. Free Radic Biol Med 31:331-335

Li H, Wu Q, Xu L, Li X, Duan J, Zhan J, Feng J, Sun X, Chen H (2015) Increased oxidative stress and disrupted small intestinal tight junctions in cigarette smoke-exposed rats. Mol Med Rep 11:4639-4644

Lundberg JON, Carlsson S, Engstrand L, Morcos E, Wiklund NP, Weitzberg E (1997) Urinary nitrite: more than a marker of infection. Urology 50:189-191

Madison MC, Landers CT, Gu B-H, Chang C-Y, Tung H-Y, You R, Hong MJ, Baghaei N, Song L-Z, Porter P, Putluri N, Salas R, Gilbert BE, Levental I, Campen MJ, Corry DB, Kheradmand F (2020) Electronic cigarettes disrupt lung lipid homeostasis and innate immunity independent of nicotine. J Clin Invest 129:4290 4304

Madretsma GS, Donze GJ, VAN Dijk APM, Tak CJAM, Wilson JHP, Zijlstra FJ (1996) Nicotine inhibits the in vitro production of interleukin 2 and tumour necrosis factor- $\alpha$ by human mononuclear cells. Immunopharmacology 35:47-51

Malago JJ, Sangu CL (2015) Intraperitoneal administration of butyrate prevents the severity of acetic acid colitis in rats. J Zhejiang Univ Sci B 16:224-234

Marczylo T (2020) How bad are e-cigarettes? What can we learn from animal exposure models? J Physiol 598:5073-5089

Mravec B, Tibensky M, Horvathova L, Babal P (2020) E-cigarettes and cancer risk. Cancer Prev Res 13:137-144

Nowarski R, Jackson R, Gagliani N, DE Zoete MR, Palm NW, Bailis W, Low JS, Harman CC, Graham M, Elinav E (2015) Epithelial IL-18 equilibrium controls barrier function in colitis. Cell 163:1444-1456

Papoutsopoulou S, Satsangi J, Campbell BJ, Probert CS (2020) Review article: impact of cigarette smoking on intestinal inflammationdirect and indirect mechanisms. Aliment Pharmacol Ther 51: $1268-1285$

Parraga G, Morissette MC (2020) E-cigarettes: what evidence links vaping to acute lung injury and respiratory failure? Canadian Journal of Respiratory, Critical Care, and Sleep Medicine 4:48-54

Pushalkar S, Paul B, Li Q, Yang J, Vasconcelos R, Makwana S, González JM, Shah S, Xie C, Janal MN (2020) Electronic cigarette aerosol modulates the oral microbiome and increases risk of infection. Iscience 23:(3)100884

Rayaman P, Rayaman E, Cevikbas A, Demirtunc R, Sehirli AO, Alagoz SG, Gurer US (2015) Effect of antibiotics on polymorphonuclear leukocyte functions and myeloperoxidase activity, glutathione and malondialdehyde levels in allergic asthma. Pol J Microbiol 64:69-72

Rouabhia M (2020) Impact of electronic cigarettes on oral health: a review. J Can Dent Assoc 86:1488-2159

Sen A, Yuksel M, Bulut G, Bitis L, Ercan F, Ozyilmaz-Yay N, Akbulut O, Cobanoğlu H, Ozkan S, Sener G (2017) Therapeutic potential of Myrtus communis Subsp. communis extract against acetic acidinduced colonic inflammation in rats. J Food Biochem 41:e12297

Sharma A, Lee J, Fonseca AG, Moshensky A, Kothari T, Sayed IM, Ibeawuchi S-R, Pranadinata RF, Ear J, Sahoo D, Crotty-Alexander LE, Ghosh P, Das S (2021) E-cigarettes compromise the gut barrier and trigger inflammation. iScience 24:102035

Sher ME, BANK, S, Greenberg R, Sardinha CT, Weissman S, Bailey B, Wexner SD (1999) The influence of cigarette smoking on cytokine levels in patients with inflammatory bowel disease. Inflamm Bowel Dis 5:73-78

Singh KP, Lawyer G, Muthumalage T, Maremanda KP, Khan NA, Mcdonough SR, Ye D, Mcintosh S, Rahman I (2019) Systemic biomarkers in electronic cigarette users: implications for noninvasive assessment of vaping-associated pulmonary injuries. ERJ Open Research:5 
Song M-A, Reisinger SA, Freudenheim JL, Brasky TM, Mathé EA, Mcelroy JP, Nickerson QA, Weng DY, Wewers MD, Shields PG (2020) Effects of electronic cigarette constituents on the human lung: a pilot clinical trial. Cancer Prev Res 13:145-152

Stewart C, Auchtung T, Ajami NJ, Velasquez K, Smith D, DE LA Garza R, Salas R, Petrosino J (2018) Effects of tobacco smoke and electronic cigarette vapor exposure on the oral and gut microbiota in humans: a pilot study. PeerJ 6

Suenaert P, Bulteel V, DEN Hond E, Geypens B, Monsuur F, Luypaerts A, Ghoos Y, Rutgeerts P (2003) In vivo influence of nicotine on human basal and NSAID-induced gut barrier function. Scand J Gastroenterol 38:399-408

Valença SS, DA Fonseca ADS, DA Hora K, Santos R, Porto LC (2004) Lung morphometry and MMP-12 expression in rats treated with intraperitoneal nicotine. Exp Toxicol Pathol 55:393-400

Verschuere S, DE Smet R, Allais L, Cuvelier CA (2012) The effect of smoking on intestinal inflammation: what can be learned from animal models? J Crohns Colitis 6:1-12

Vona R, Pallotta L, Cappelletti M, Severi C, Matarrese P (2021) The Impact of oxidative stress in human pathology: focus on gastrointestinal disorders. Antioxidants (Basel, Switzerland) 10:201
Wang H, Zhao J-X, Hu N, Ren J, Du M, Zhu M-J (2012) Side-stream smoking reduces intestinal inflammation and increases expression of tight junction proteins. World J Gastroenterol: WJG 18:2180 2187

Wang B, Wu Z, Ji Y, Sun K, Dai Z, Wu G (2016) L-glutamine enhances tight junction integrity by activating CaMK kinase 2-AMP-activated protein kinase signaling in intestinal porcine epithelial cells. J Nutr 146:501-508

Yang J, Liu XX, Fan H, Tang Q, Shou ZX, Zuo DM, Zou Z, Xu M, Chen QY, Peng Y, Deng SJ, Liu YJ (2015) Extracellular vesicles derived from bone marrow mesenchymal stem cells protect against experimental colitis via attenuating colon inflammation, oxidative stress and apoptosis. PLoS One 10:e0140551

Zucker SD, Vogel ME, Kindel TL, Smith DL, Idelman G, Avissar U, Kakarlapudi G, Masnovi ME (2015) Bilirubin prevents acute DSSinduced colitis by inhibiting leukocyte infiltration and suppressing upregulation of inducible nitric oxide synthase. Am J Physiol Gastrointest Liver Physiol 309:G841-G854

Publisher's note Springer Nature remains neutral with regard to jurisdictional claims in published maps and institutional affiliations. 